\title{
Ágar e carvão ativado influenciam no desenvolvimento in vitro da parte aérea e radicular de sequoia
}

\author{
Agar and activated charcoal influence the in vitro development of shoot and root sequoia
}

\author{
Aline Meneguzzi, Samila Silva Camargo, Marcio Carlos Navroski, Mariane de Oliveira Pereira, \\ Patricia Fukushima Souza, Leo Rufato
}

Universidade do Estado de Santa Catarina, Lages, SC. Brasil. *Autor para correspondência: alinemeneguzzi@yahoo.com.br

\begin{abstract}
RESUMO
Plantios experimentais com Sequoia sempervirens (Lamb), espécie conhecida mundialmente pelo grande porte, longevidade e qualidade madeireira, estão iniciando no Brasil, tornando necessário a disponibilidade de mudas de qualidade. Assim, a técnica de cultura de tecidos, via micropropagação, se torna uma grande aliada pela garantia de superioridade genética, produção em grande escala e tempo reduzido de propagação. Atualmente há inúmeros protocolos para diversas espécies, porém, é necessário verificar todos os agentes influentes no sucesso do desenvolvimento in vitro. O objetivo deste trabalho foi determinar a influência do carvão ativado e de concentrações de ágar no desenvolvimento in vitro aéreo e de raízes de $S$. sempervirens. Os tratamentos realizados envolveram a presença/ausência do carvão ativado $\left(1 \mathrm{~g} \mathrm{~L}^{-1}\right)$, combinados com concentrações de ágar $\left(4,5 \mathrm{e} \mathrm{g} \mathrm{L}^{-1}\right)$ em meio MS 50\%. Para o número e comprimento de brotos e de raízes, apenas o carvão ativado foi significativo, sendo que a presença beneficiou o desenvolvimento dos explantes. Para porcentagem de calo, houve interação dos fatores, sendo que maiores concentrações de ágar ( 5 e $\left.6 \mathrm{~g} \mathrm{~L}^{-1}\right)$ na presença do carvão foram prejudiciais, pois apresentaram maior calosidade, o que minimiza as taxas de enraizamento. Indica-se a adição de carvão ativado $\left(1 \mathrm{~g} \mathrm{~L}^{-1}\right)$ e de menor concentração de ágar (4 $\left.\mathrm{g} \mathrm{L}^{-1}\right)$ em meio de cultura MS 50\% para um melhor desenvolvimento in vitro de sequoia.
\end{abstract}

PALAVRAS-CHAVE: Sequoia sempervirens (Lamb), espécie lenhosa, micropropagação, enraizamento in vitro.

\begin{abstract}
Experimental seedlings with Sequoia sempervirens (Lamb), a species known worldwide for its large size, longevity and quality of timber, are beginning in Brazil, making the availability of quality seedlings necessary. Thus, the technique of tissue culture, via micropropagation, becomes a great ally for the guarantee of genetic superiority, large-scale production and reduced propagation time. Currently there are numerous protocols for several species, however, it is necessary to verify all influential agents in the success of in vitro development. The objective of this work was to determine the influence of activated charcoal and agar concentrations on aerial and root development of $S$. sempervirens. The treatments involved the presence / absence of activated carbon $\left(1 \mathrm{~g} \mathrm{~L}^{-1}\right)$, combined with concentrations of agar (4, 5 and $6 \mathrm{~g} \mathrm{~L}^{-1}$ ) in $50 \% \mathrm{MS}$ medium. For the number and length of shoots and roots, only activated carbon was significant, and the presence benefited the development of the explants. For the percentage of callus, there was interaction of the factors, and higher concentrations of agar (5 and $\left.6 \mathrm{~g} \mathrm{~L}^{-1}\right)$ in the presence of medium were harmful, since they presented higher callosity, which minimizes the rooting rates. It is indicated the addition of activated charcoal $\left(1 \mathrm{~g} \mathrm{~L}^{-1}\right)$ and lower concentration of agar $\left(4 \mathrm{~g} \mathrm{~L}^{-1}\right)$ in $50 \%$ MS culture medium for a better in vitro development of sequoia.
\end{abstract}

KEYWORDS: Sequoia sempervirens (Lamb), woody species, micropropagation, rooting in vitro.

\section{INTRODUÇÃO}

A espécie Sequoia sempervirens (Lamb), também conhecida como redwood, nativa da América do Norte, tem destaque mundial pelo seu grande porte, longevidade e qualidade madeireira e já é cultivada com sucesso em muitos países (LIU et al. 2006). No Brasil, a sequoia foi plantada apenas para fins de arborização. Por ser uma espécie de clima temperado, NAVROSKI et al. (2015) destacam a importância de testes silviculturais no sul do país, especialmente em regiões de maior altitude, já que o 
desenvolvimento de algumas espécies de Eucalyptus, por exemplo, é prejudicado em razão da ocorrência de fortes geadas.

Assim, a produção de mudas de sequoias, com qualidade, já adaptadas ao Brasil é essencial para realizar pesquisas sobre o crescimento e desenvolvimento desta espécie em plantios comerciais. Entretanto, a principal forma de propagação, via sementes, apresenta entraves como baixa taxa de germinação (média de 10\%) e baixa sobrevivência de plântulas (BOE 1974). Além disso, segundo estudos, plantas jovens, que é o caso das matrizes no Brasil, produzem sementes com menor viabilidade. Segundo OLSON et al. (1990) a maior viabilidade de sementes de sequoia foi obtida em árvores com 250 anos de idade.

Com isso, a cultura de tecidos, via a técnica de micropropagação, surge como uma alternativa altamente viável, pois possibilita a produção de um grande número de plantas assépticas em um curto espaço de tempo (GRATTAPAGLIA \& MACHADO 1998), além de manutenção da fidelidade genética em relação às árvores matrizes.

O processo de elaboração de um protocolo de micropropagação depende do controle de inúmeras variáveis. Para isso, vários fatores (físicos, fisiológicos, genéticos, etc) devem ser testados, a fim de se encontrar um protocolo com eficiência, praticidade e custo compatível. Uma das maiores limitações ao uso da micropropagação têm sido o baixo enraizamento das partes regeneradas in vitro, onde diferentemente das plantas herbáceas, na maioria das espécies lenhosas, o processo de rizogênese não foi ainda elucidado (OLIVEIRA et al. 2013).

Dentre os fatores que interferem no desenvolvimento in vitro das raízes e na sobrevivência deste material quando transplantado para o meio ex vitro, está o uso do carvão ativado no meio de cultura, durante a fase de enraizamento. Este agente é conhecido por favorecer o crescimento de raízes, adsorver substâncias inibitórias ao desenvolvimento e de liberar substâncias naturais que beneficiam o crescimento das culturas (GUSON et al. 2012). Além disto, o estado físico do meio de cultivo é notadamente conhecido por influenciar o crescimento de plantas in vitro. O ágar, polímero utilizado para solidificar o meio de cultura, pode interferir nas características das raízes formadas e consequentemente no sucesso do transplante e sobrevivência das mudas micropropagadas (TIBOLA et al. 2004).

O objetivo deste trabalho foi testar a presença do carvão ativado e de diferentes concentrações de ágar no desenvolvimento aéreo e de raízes in vitro de sequoia.

\section{MATERIAL E MÉTODOS}

Como fontes de propágulos para a micropropagação foram utilizadas minicepas de matrizes selecionadas de sequoia, de aproximadamente 40 anos de idade, localizadas na Floresta Nacional (Flona) de São Francisco de Paula, RS, as quais foram propagadas pelo processo de estaquia convencional após 120 dias do anelamento parcial ou completo da árvore matriz. Para tanto, as estacas foram coletadas das árvores matrizes e transportadas até o Viveiro Florestal do Centro de Ciências Agroveterinárias (CAV) da Universidade do Estado de Santa Catarina (UDESC). Cinco meses após a estaquia, as plantas enraizadas foram aclimatadas e conduzidas para o estabelecimento do minijardim clonal. Mensalmente, durante quatro meses, realizou-se a poda de formação das minicepas.

Brotações juvenis (herbáceas) provenientes das minicepas do jardim clonal de sequoia foram utilizadas como material vegetal para o estabelecimento in vitro. Este material foi individualizado em segmentos nodais de aproximadamente $2 \mathrm{~cm}$ de comprimento e previamente limpos em água corrente (por 10 minutos) e detergente neutro. Em câmara de fluxo laminar ocorreu a assepsia com imersão em álcool $70 \%$ por um minuto, seguido de solução de hipoclorito de sódio (2,5\% de cloro ativo) durante 15 minutos, por fim, lavados três vezes em água destilada autoclavada.

Em todas as etapas o meio de cultivo utilizado foi MS (MURASHIGE \& SOOG 1962) com a metade da concentração original de sais (MS 50\%) e, além dos sais e vitaminas característicos deste meio de cultivo, foram adicionados $30 \mathrm{~g} \mathrm{~L}^{-1}$ de sacarose e $0,1 \mathrm{~g} \mathrm{~L}^{-1}$ de mio-inositol e o pH ajustado para 5,8 antes da inclusão do ágar. Como protocolo, antes da utilização, os frascos de $200 \mathrm{~mL}$ de capacidade de volume, com $30 \mathrm{~mL}$ meio de cultura, foram autoclavados a $121^{\circ} \mathrm{C}$ e e $1,5 \mathrm{~atm}$ de pressão, por 20 minutos.

Após a inoculação dos segmentos nodais de sequoia em meio de cultura, o material foi armazenado no escuro por sete dias e depois permaneceram em sala de crescimento, com condições controladas de $42 \mu \mathrm{mol} \mathrm{m} \mathrm{s}^{-1}$ de intensidade luminosa, fotoperíodo de 16 horas e temperatura de $25 \pm 2{ }^{\circ} \mathrm{C}$. Com 30 dias de cultivo estes segmentos nodais apresentaram brotações que foram multiplicadas em novos frascos contendo o mesmo meio de cultura (MS 50\%) adicionado de $1 \mathrm{mg} \mathrm{L}^{-1}$ de BAP (6 benzilaminopurina). Posteriormente, estes materiais com novas brotações foram utilizados para a realização deste 
experimento.

Os explantes de sequoia foram padronizados em tamanho aproximado de $2 \mathrm{~cm}$. Os tratamentos estudados foram dois fatores: presença/ausência do carvão ativado $\left(1 \mathrm{~g} \mathrm{~L}^{-1}\right)$ e concentrações de ágar $(4,5$ e $6 \mathrm{~g} \mathrm{~L}^{-1}$ ) em meio de cultura MS 50\%. O delineamento foi inteiramente casualizado em fatorial $2 \times 3$, com seis repetições de cinco explantes por tratamento.

Após 60 dias de cultivo, as variáveis avaliadas foram: número médio de brotos por explante; comprimento médio de brotos $(\mathrm{cm})$; número de raízes; comprimento médio das raízes $(\mathrm{cm})$ e a presença de calo. Os dados obtidos foram submetidos à análise de variância, e quando significativos pelo teste de $\mathrm{F}$ $(p<0,05)$ foram submetidos ao teste de Tukey a $5 \%$ de probabilidade de erro, empregando o programa estatístico SISVAR (FERREIRA 2011).

\section{RESULTADOS E DISCUSSÃO}

Não houve interação dos fatores testados (ágar $x$ carvão ativado) para número e comprimento $(\mathrm{cm})$ dos brotos e das raízes, sendo que para estas variáveis somente a presença do carvão ativado no meio de cultura influenciou $(p<0,05)$ no desenvolvimento in vitro dos explantes (Tabela 1$)$.

Tabela 1. Número e comprimento de brotos $(\mathrm{cm})$ e de raízes de explantes de sequoia in vitro cultivados em meio MS 50\% adicionado ou não de carvão ativado $\left(1 \mathrm{~g} \mathrm{~L}^{-1}\right)$.

Table 1. Number and length of shoot $(\mathrm{cm})$ and roots of in vitro seed explants cultivated in $50 \%$ MS medium added or not of activated charcoal $\left(1 \mathrm{~g} \mathrm{~L}^{-1}\right)$.

\begin{tabular}{cccrc}
\hline Carvão ativado $\left(1 \mathrm{~g} \mathrm{~L}^{-1}\right)$ & № de brotos & Comp. brotos $(\mathrm{cm})$ & № de raízes & Comp. raízes $(\mathrm{cm})$ \\
\hline Presença & $4,74 \mathrm{a}^{*}$ & $6,27 \mathrm{a}$ & $0,78 \mathrm{a}$ & $0,76 \mathrm{a}$ \\
Ausência & $3,69 \mathrm{~b}$ & $2,92 \mathrm{~b}$ & $0,24 \mathrm{~b}$ & $0,13 \mathrm{~b}$ \\
\hline
\end{tabular}

${ }^{*}$ Médias seguidas por letras diferentes na coluna diferem entre si pelo Teste de Tukey $(p<0,05)$.

O carvão ativado normalmente é adicionado ao meio de cultura em concentrações que variam de $0,2 \%$ a $3 \%$, porém sua presença pode promover ou inibir o crescimento in vitro, dependendo da espécie e do tecido utilizado (VILLA et al. 2007). Neste trabalho a adição de $1 \mathrm{~g} \mathrm{~L}^{-1}$ de carvão ativado ao meio de cultura teve as melhores respostas no desenvolvimento da parte aérea e de raízes, quando comparado à ausência deste produto.

Estes benefícios no desenvolvimento in vitro vegetal podem ser explicados pela capacidade de adsorção do carvão ativado. Plântulas cultivadas em meio base, que é composto por sais minerais (macros e micronutrientes), sacarose, vitaminas e mio-inositol, possuem uma capacidade de absorção seletiva limitada, influenciada pela acidificação do meio, em virtude do metabolismo celular, podendo incorporar elementos não essenciais e/ou mesmo tóxicos como compostos fenólicos que podem levar até a morte da cultura (KERBAUY 2004, MULLER et al. 2007). Assim, a adição de carvão ativado pode impedir a acidificação do meio de cultivo, além de estabilizar o $\mathrm{pH}$ do meio e ainda pode servir como fonte alternativa de carbono para a cultura.

A adição de carvão ativado na etapa de enraizamento in vitro também foi testada por outros autores. $\mathrm{O}$ uso de concentrações crescentes $\left(1 \mathrm{a} 3 \mathrm{~g} \mathrm{~L}^{-1}\right)$ no cultivo in vitro de bananeira resultou em maior vigor radicular, além de maior número de raízes (COSTA et al. 2006). Resultado semelhante também foi encontrado para orquídea (Cattleya pumila) na qual a concentração de $1 \mathrm{~g} \mathrm{~L}^{-1}$ apresentou incremento na altura total das plântulas e no comprimento da raiz principal (GUSON et al. 2012). Já SARTOR et al. (2013) concluiu que o uso de carvão ativado, também na concentração de $1 \mathrm{~g} \mathrm{~L}^{-1}$, não influenciou no cultivo in vitro de Jacarandá da Bahia (Dalbergia nigra).

Em contrapartida, VILLA et al. (2007) ao testar diferentes concentrações $\left(0 ; 1,0 ; 2,0 ; 3,0\right.$ e 4,0 $\left.\mathrm{g} \mathrm{L}^{-1}\right)$ de carvão ativado em duas frutíferas de clima temperado, amoreira preta (Rubus spp.) e videira (Vitis sp.), concluiu que a presença do carvão ativado inibiu a multiplicação das brotações e crescimento de parte aérea e radicular. A adição de carvão ativado ao meio de cultura pode promover ou inibir o crescimento in vitro, conforme a espécie e o tipo de tecido utilizado, além da fonte do carvão, pureza e grau de ativação (PAN \& STADEN 1998). Segundo os mesmos autores, a adsorção não-seletiva do carvão ativado, como por exemplo, em relação às vitaminas (tiamina, ácido nicotínico, piridoxina), além de quelatos de ferro e zinco, podem resultar em efeitos negativos para algumas espécies in vitro.

Para a variável porcentagem de calos houve interação dos fatores $(p<0,05)$ carvão ativado e concentração de ágar (Tabela 2). A presença do carvão ativado e maiores concentrações (5 e $\left.6 \mathrm{~g} \mathrm{~L}^{-1}\right)$ de ágar no meio de cultivo resultaram em maiores porcentagens (77 e 66\%, respectivamente) de calos nos 
explantes de sequoia.

Tabela 2. Calogênese (\%) em explantes de sequoia in vitro cultivados em meio MS $50 \%$ com diferentes concentrações de ágar $\left(4,5\right.$ e $\left.6 \mathrm{~g} \mathrm{~L}^{-1}\right)$ e da adição de carvão ativado $\left(1 \mathrm{~g} \mathrm{~L}^{-1}\right)$.

Table 2. Calo (\%) in in vitro sequoia explants cultured in 50\% MS medium with different concentrations of agar $\left(4,5\right.$ and $\left.6 \mathrm{gL}^{-1}\right)$ and the addition of activated carbon $\left(1 \mathrm{~g} \mathrm{~L}^{-1}\right)$.

\begin{tabular}{ccc}
\hline Concentrações & \multicolumn{2}{c}{ Carvão ativado $\left(1 \mathrm{~g} \mathrm{~L}^{-1}\right)$} \\
\cline { 2 - 3 } de ágar $\left(\mathrm{g} \mathrm{L}^{-1}\right)$ & Presença $(\%)$ & Ausência $(\%)$ \\
\hline 4 & $33,00 \mathrm{Aa}^{*}$ & $0,01 \mathrm{Ba}$ \\
5 & $77,00 \mathrm{Ab}$ & $1,00 \mathrm{Ba}$ \\
6 & $66,00 \mathrm{Ab}$ & $11,00 \mathrm{Ba}$ \\
\hline
\end{tabular}

*Médias seguidas por letras minúsculas diferentes na coluna ou maiúsculas na linha diferem entre si pelo Teste de Tukey $(p<0,05)$.

Em plantas cultivadas in vitro, as raízes adventícias podem ser formadas, na fase de multiplicação, a partir de células de parênquima localizadas nas partes aéreas. Nessa condição a rizogênese pode ocorrer de modo direto ou indireto a partir de calos (GRATTAPAGLIA \& MACHADO 1998). A calogênese na base dos explantes foi um processo recorrente durante todo o cultivo in vitro de sequoia (Figura 1 ).

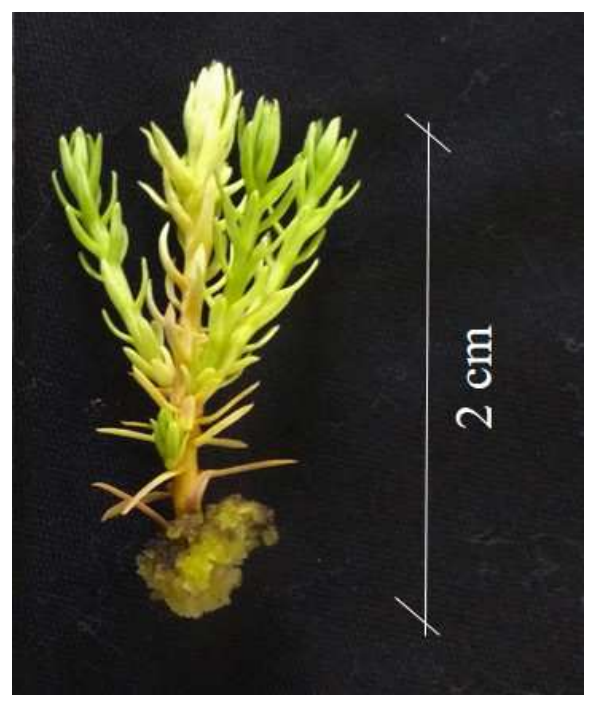

Figura 1. Formação de calos na base de explantes de sequoia cultivados em meio MS 50\%.

Figure 1. Formation of callus in the base of sequoia explants grown in $50 \%$ MS medium.

A capacidade dos tecidos para formação de raízes depende de vários fatores endógenos e/ou exógenos e suas interações. Dentre estes fatores está a presença de substâncias como carvão ativado e o ágar, que podem interferir no desenvolvimento fisiológico e nas condições ambientais de crescimento do explante (SOUZA \& PEREIRA 2007).

A luminosidade é um fator que normalmente influencia na indução de raízes. A presença do carvão no meio de cultivo pode simular fisicamente a condição de escuro, no qual as raízes podem se desenvolver melhor (GRATTAPAGLIA \& MACHADO 1998) porém, concentrações elevadas de carvão ativado podem até mesmo impedir o processo de enraizamento. Segundo LEITZKE et al. (2009) com o aumento da concentração de carvão ativado $\left(0,10\right.$ e $\left.20 \mathrm{~g} \mathrm{~L}^{-1}\right)$ houve uma redução na porcentagem de enraizamento e no comprimento médio das raízes de amoreira preta 'Xavante'. Já NEPOMUCENO et al. (2009), verificaram efeito positivo da adição do carvão sobre o número de raízes secundárias no cultivo in vitro de angico (Anadenanthera colubrina).

Sobre a influência do estado físico do meio de cultura, tem-se observado que algumas espécies podem estabelecer um sistema radicular mais vigoroso, quando cultivados em meio líquido com alguma fonte de aeração, como pontes de papel ou meio sob agitação. Embora o meio líquido interfira positivamente na disponibilidade de água, nutrientes, hormônios e níveis de oxigênio, a grande maioria dos protocolos de micropropagação é estabelecida em meio de cultura semi-sólido (SOUZA \& PEREIRA 2007). 
Altas concentrações de ágar podem ter efeito inibitório sobre a indução de raízes adventícias in vitro, sendo as causas exatas ainda não conhecidas. TIBOLA et al. (2004) atribuíram a possibilidade dos explantes não possuírem pêlos radiculares devidamente desenvolvidos, pela falta de oxigênio em meios solidificados com altas concentrações de ágar.

De acordo com HARTMANN et al. (2002), um meio de cultivo adequado para o enraizamento deve ser suficientemente poroso, a fim de permitir trocas gasosas eficientes. Possivelmente a menor concentração de ágar $\left(4 \mathrm{~g} \mathrm{~L}^{-1}\right)$, testada neste trabalho, que tornou o meio semissólido, proporcionou uma melhor motilidade dos nutrientes e gases no cultivo in vitro resultando nos melhores resultados quando comparado a maiores concentrações de ágar e um meio mais sólido. Além disto, a utilização de menor concentração de ágar resulta em menores custos na produção final da muda.

\section{CONCLUSÃO}

$\mathrm{Na}$ etapa de enraizamento in vitro de sequoia recomenda-se a adição de carvão ativado $\left(1 \mathrm{~g} \mathrm{~L}^{-1}\right)$ e baixa concentração de ágar $\left(4 \mathrm{~g} \mathrm{~L}^{-1}\right)$ em meio de cultura MS $50 \%$ pois favorece o desenvolvimento da parte aérea e das raízes.

\section{AGRADECIMENTOS}

A Coordenação de Aperfeiçoamento de Pessoal de Nível Superior (CAPES) pelo apoio financeiro e ao Centro de Ciências Agroveterinárias/Universidade do Estado de Santa Catarina (CAV/UDESC) pela estrutura e condições fornecidas para a execução do trabalho.

\section{REFERÊNCIAS}

BOE KN. 1974. Sequoia sempervirens (D. Don) Endl. In: SCHOPMEYER CS. (Ed.). Seeds of woody plants in the United States. Agriculture Handbook 450. Washington: USDA Forest Service. p.764-766.

COSTA FHS et al. 2006. Efeito da interação entre carvão ativado e N6 - benzilaminopurina na propagação in vitro de bananeira, CV. Grande Naine (AAA). Revista Brasileira de Fruticultura 28: 280-283.

FERREIRA DF. 2011. Sisvar: A computer statistical analysis system. Ciência e Agrotecnologia 35: 1039-1042.

GRATTAPAGLIA MA. 1998. Micropropagação. In: TORRES AC et al. (Eds.). Cultura de tecidos e transformação genética de plantas. Brasília: Embrapa. p.183-260.

GUSON RR et al. 2012. Influência de diferentes concentrações de carvão ativado no crescimento e enraizamento in vitro de Cattleya pumila Hook. Revista em Agronegócios e Meio Ambiente 5: 551-563.

HARTMANN HT et al. 2002. Plant propagation: principles and practices. 7.ed. New Jersey: Prentice Hall. 880p.

KERBAUY GB. 2004. Fisiologia vegetal. Rio de Janeiro: Guanabara-Koogan. 452p.

LEITZKE LN et al. 2009. Multiplicação e enraizamento in vitro de amoreira-preta 'xavante': efeito da concentração de sais, do tipo de explante e de carvão ativado no meio de cultura. Ciência e Agrotecnologia 33: 1959-1966.

LIU C et al. 2006. Shoot regeneration and somatic embryogenesis from needles of redwood (Sequoia sempervirens (D.Don.) Endl.). Plant Cell Reports 25: 621-628.

MULLER TS et al. 2007. Crescimento in vitro e aclimatação de plântulas de Miltonia flavences. Revista Brasileira de Biociências 5: 252-254.

MURASHIGE T \& SKOOG F. 1962. A revised medium for rapid growth and bioassay with tobacco tissue cultures. Physiology Plant 15: 473-497.

NAVROSKI MC et al. 2015. Resgate e propagação vegetativa de Sequoia sempervirens. Revista Floresta 45: 383392.

NEPOMUCENO FC et al. 2009. Respostas morfofisiológicas in vitro de plântulas de Anadenanthera colubrina (Vell.) Brenan var. cebil (Griseb) Altschul. Revista Árvore 33: 481-490.

OLIVEIRA LS et al. 2013. Micropropagação de espécies florestais brasileiras. Pesquisa Florestal Brasileira 33: 439453.

OLSON DF et al. 1990. Sequoia sempervirens (D. Don) Endl. redwoods. In: BURNS R et al. (Eds.). Silvics of North America. Washington: USDA. p. 541-551.

PAN MJ \& STADEN JV. 1998. The use of charcoal in in vitro culture - a review. Plant Growth Regulation 26: 155-163.

TIBOLA CT et al. 2004. Diferentes meios de cultivo no enraizamento in vitro de de Prunus sp. Revista Brasileira de Agrociência 10: 191-195.

SARTOR RF et al. 2013. Diferentes meios de cultura e antioxidantes no estabelecimento in vitro do Jacarandá da Bahia. Bioscience Journal 29: 408-411.

SOUZA AV \& PEREIRA AMS. 2007. Enraizamento de plantas cultivadas in vitro. Revista Brasileira de Plantas Medicinais 9: 103-117.

VILLA F et al. 2007. Influência do carvão ativado e BAP na multiplicação in vitro de duas frutíferas de clima temperado. Revista Ceres 54: 118-124. 